
\title{
is Research Square \\ Life-threatening, delayed epistaxis after Le Fort I osteotomy: a case report
}

\section{Amir Eleuch ( $\sim$ Eleuch-amir@hotmail.com )}

Universite de Tunis El Manar Faculte de Medecine de Tunis https://orcid.org/0000-0001-7460-7989

\section{Maha Ben Rejeb}

Universite de Sousse Faculte de Medecine de Sousse

\section{Anis Ayadi}

Universite de Sousse Faculte de Medecine de Sousse

\section{Samia Ayachi}

Universite de Sousse Faculte de Medecine de Sousse

\section{Ramzi Moatemri}

Universite de Sousse Faculte de Medecine de Sousse

Habib Khochtali

Universite de Sousse Faculte de Medecine de Sousse

\section{Research Article}

Keywords: Orthognathic surgery, Lefort osteotomy, Pseudoaneurysm, Postoperative complication

Posted Date: May 3rd, 2021

DOl: https://doi.org/10.21203/rs.3.rs-485729/v1

License: (c) (i) This work is licensed under a Creative Commons Attribution 4.0 International License. Read Full License 


\section{Abstract}

Introduction: When performing a Le Fort 1 osteotomy, there is always a risk of injuring the internal maxillary artery or one of its branches. This diagnosis should be considered when confronted to recurrent or massive epistaxis following surgery.

Case presentation: The authors present a case of a life-threatening, delayed and massive epistaxis caused by a ruptured pseudoaneuvrysm of the right sphenopalatine artery as a post-operative complication of a Le Fort I osteotomy successfully managed by anterior and posterior nasal packing.

Conclusion: Despite its simplicity and attested reliability, Le Fort I osteotomy is not completely free of complications.

\section{Introduction}

The Le Fort I osteotomy is one of the most commonly used procedures to correct dentofacial deformities[1]. Despite its simplicity and attested reliability, this procedure is not completely free of complications[2]. Most of which are fortunately benign. Nevertheless, major intraoperative and postoperative bleeding may occur and can be life-threatening. The authors present a case of a delayed and massive epistaxis caused by a ruptured pseudoaneuvrysm of the right sphenopalatine artery as a post-operative complication of a Le Fort I osteotomy.

\section{Case Presentation}

A 17-year-old female, born with a left unilateral cleft lip repaired in infancy with no other concomitant pathology, underwent in our department a Le Fort I osteotomy with advancement to correct a class III malocclusion (Figure 1). The patient was transferred in stable condition immediately after surgery to our unit for monitoring. As no incidents were noted intraoperatively and postoperatively, the patient was discharged from the hospital on the second day. Two weeks later, she presented to the emergency room of our hospital with a bilateral epistaxis. The patient was hemodynamically stable. Laboratory investigations were normal with a haemoglobin of $11 \mathrm{~g} / \mathrm{dl}$. The bleeding was controlled by a bilateral anterior nasal packing, and she was subsequently transferred to our unit for observation.

During the second day of her admission, she became pale and tachycardic (rate $110 \mathrm{bpm}$ ) with a blood pressure of 100/69 mmHg and a continuous posterior nasal bleeding was noted. Complete blood count showed that her haemoglobin had dropped to $6.3 \mathrm{~g} / \mathrm{dl}$. This required treatment by bilateral anterior and posterior nasal packing under general anaesthesia along with volume resuscitation and transfusion of three units of packed red blood cells. After hemodynamic stabilization and control of nasal bleeding, an angiography was performed revealing a ruptured pseudoaneuvrysm of the right sphenopalatine artery (Figure 2). The therapeutic decision was to maintain the packing, to keep the patient under close observation and to realize a therapeutic embolization if required. After one week of hospitalisation, the 
patient was hemodynamically stable and the bleeding did not recur. The packing was then removed. No incidents were noted during 72 hours and the patient was discharged from hospital.

\section{Discussion}

Complications following Le Fort osteotomy are relatively rare compared to the number of procedures performed[3]. Fortunately, most of them are not severe. In a study conducted by Politis, on 750 Le Fort I osteotomies, only two cases of life-threatening bleeding have been reported[4]. However, as the author pointed out, such complications could be underestimated, since patients experiencing massive nasal bleeding will not be treated necessarily in the same hospital or by the same surgeon.

During Le Fort I osteotomies and more precisely at the moment of pterygomaxillary separation, damage to the internal maxillary artery or one of its branches, may occur. Bendrihem and Vacher performed a tomodensitometric study to measure the position of maxillary artery in relation to pterygomaxillary junction. They concluded that there is a risk of injuring the maxillary artery $18 \mathrm{~mm}$ above the inferior extremity of the pterygomaxillary junction[5]. It is to say how much we are close when performing pterygomaxillary separation. In general, damage to vessels causes an acute bleeding which can be controlled intraoperatively. But, in other situations, where the vessels are partially injured, a weak point on the vessel wall can lead to the formation of a pseudoaneuvrysm which may result in a delayed postoperative bleeding when it ruptures[6]. For our patient and for most of the patients with this condition, bleeding occurs within the first 14 days post-operatively. Elsewhere, longer delays up to 3 months postoperatively have been reported[7]. The diagnosis of pseudoaneuvrysm is strongly suggested by patients' history. Angiography confirm the diagnosis, locate precisely the site of bleeding and treat on the same occasion if necessarily. In the management of this case, it was elected not to perform an embolization because adequate haemostasis was achieved with anterior and posterior nasal packing.

\section{Conclusion}

Delayed postoperative epistaxis complicating Le Fort I osteotomy is an uncommon event, nevertheless physicians should consider damage of the maxillary artery or its branches when facing recurrent or persistent bleeding postoperatively.

\section{Declarations}

\section{Funding}

This research received no specific grant from any funding agency in the public, commercial, or not-forprofit sectors.

\section{Conflict of interest}

The Authors declare that there is no conflict of interest. 


\section{Ethical approval}

Not applicable.

\section{Consent for publication}

The patient and family provided consent for publication of this case report.

\section{Acknowledgments:}

The authors would like to thank Professor Amel Jarraya Eleuch for the English language review.

\section{References}

1. Buchanan EP, Hyman CH (2013) LeFort I Osteotomy. Semin Plast Surg 27:149-154. https://doi.org/10.1055/s-0033-1357112

2. Eshghpour M, Mianbandi V, Samieirad S (2018) Intra- and Postoperative Complications of Le Fort I Maxillary Osteotomy. J Craniofac Surg 29:1. https://doi.org/10.1097/SCS.0000000000004828

3. Lanigan DT, Hey JH, West RA (1991) Major vascular complications of orthognathic surgery: False aneurysms and arteriovenous fistulas following orthognathic surgery. J Oral Maxillofac Surg 49:571-577. https://doi.org/10.1016/0278-2391(91)90337-L

4. Politis C (2012) Life-threatening haemorrhage after 750 Le Fort I osteotomies and 376 SARPE procedures. Int J Oral Maxillofac Surg 41:702-708. https://doi.org/10.1016/j.ijom.2012.02.015

5. Bendrihem R, Vacher C (2017) Radiologic anatomy of the maxillary artery in the pterygopalatine area applied to Le Fort 1 osteotomies. Surg Radiol Anat 39:23-27. https://doi.org/10.1007/s00276-0161697-7

6. Avelar RL, Goelzer JG, Becker OE, et al (2010) Embolization of Pseudoaneurysm of the Internal Maxillary Artery After Orthognathic Surgery. J Craniofac Surg 21:

7. Bykowski MR, Hill A, Garland C, et al (2018) Ruptured Pseudoaneurysm of the Maxillary Artery and Its Branches Following Le Fort I Osteotomy: Evidence-Based Guidelines. J Craniofac Surg 29:

\section{Figures}



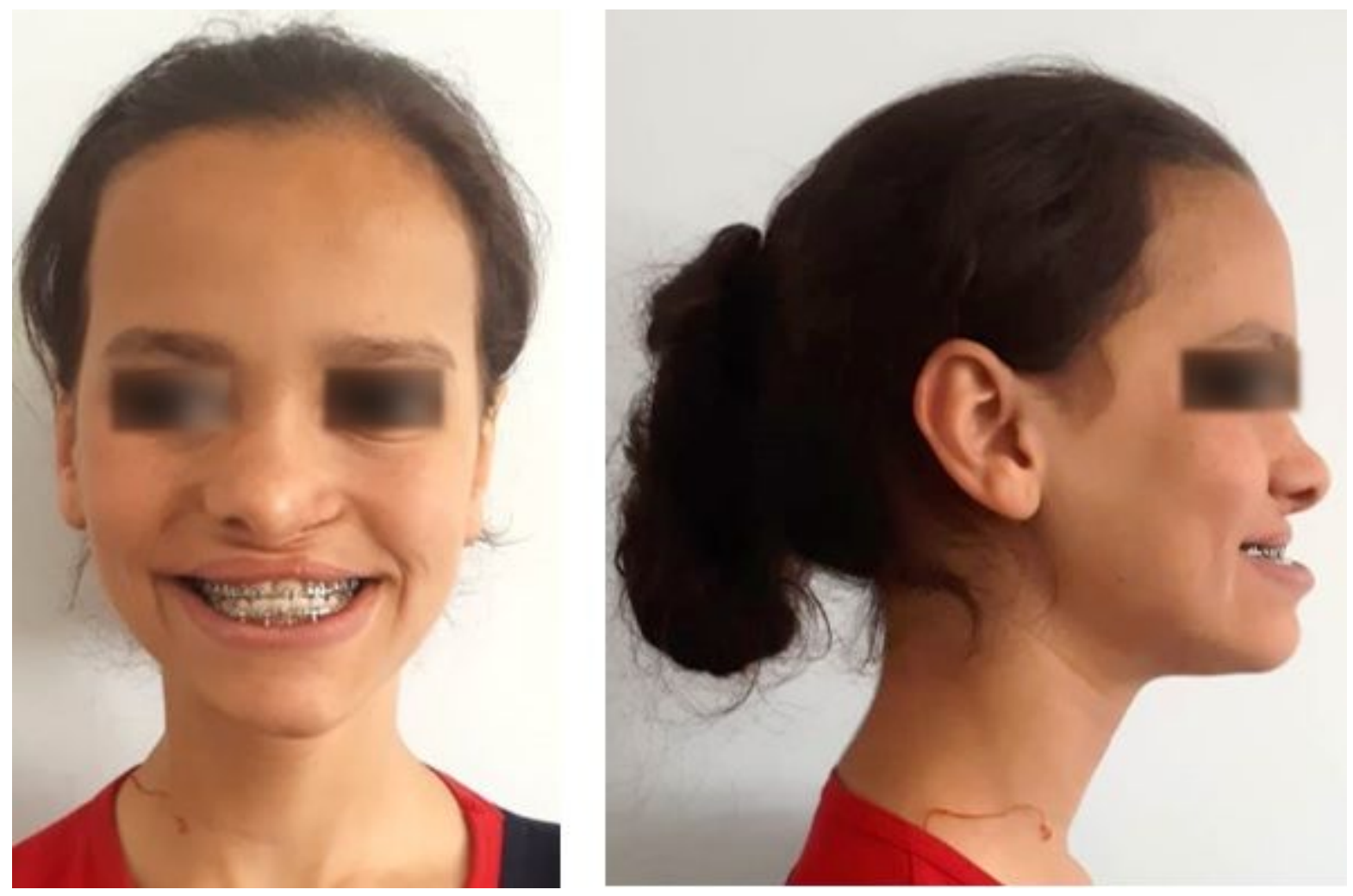

Figure 1

Preoperative views demonstrating dentofacial deformity

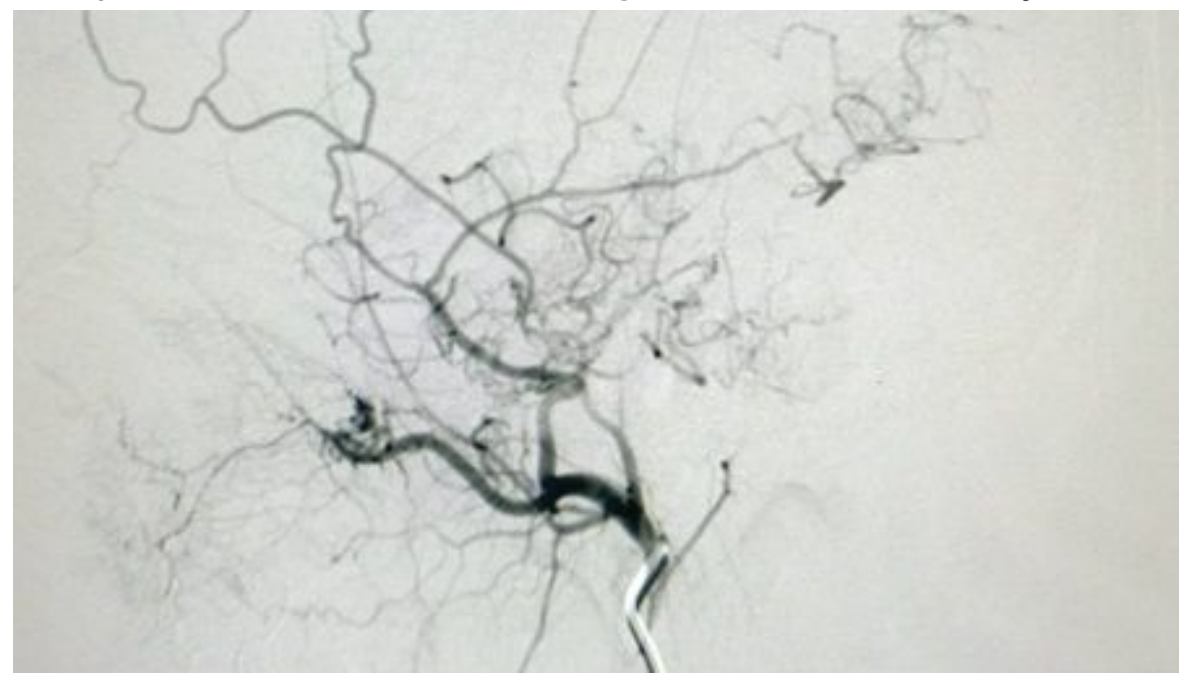

\section{Figure 2}

Arteriography of the right external carotid. The pseudoaneuvrysm is located on the right sphenopalatine artery 